\title{
Adsorptive Removal of Cs(I) from Water by Using Persimmon Tannin Impregnated Zeolite
}

\author{
Hari Paudyal $^{*}$ Bimala Pangeni $^{2}$ and Katsutoshi Inoue ${ }^{3}$ \\ ${ }^{1}$ Central Department of Chemistry, Tribhuvan University, Kirtipur Kathmandu, Nepal \\ ${ }^{2}$ Department of Botany, Trichandra Multiple Campus, Tribhuvan University, Kathmandu, Nepal \\ ${ }^{3}$ Department of Applied Chemistry, Saga University, Honjo 1, Saga 840-8502, Japan \\ E-mail: hpaudyal@cdctu.edu.np
}

\begin{abstract}
In the present work, the presence of exchangeable cation in zeolite and polyhydroxy groups in persimmon tannin were utilized for the adsorption of Cs(I) using persimmon tannin impregnated zeolite abbreviated hereafter as PTIZ. Batch experiments were conducted to determine the binding ability of PTIZ for the Cs(I) ion. The best Cs(I) removal results was obtained when $p H$ of the solution was adjusted higher than 5. The rate of Cs(I) uptake by PTIZ was fast at the beginning and reached adsorption equilibrium within 1h. Maximum uptake capacity and Langmuir equilibrium constant were found to be $1.24 \mathrm{mmol} / \mathrm{g}$ and $3.34 \mathrm{~L} / \mathrm{mmoL}$, respectively. The removal Cs(I) by PTIZ is inferred to be ion exchange as well as chelation mechanism. The complete or 100\% removal of Cs(I) from water was successfully achieved by using small amount of PTIZ. Thus, the PTIZ can be expected to be a promising adsorbent for the treatment of effluent containing trace amount of $C s(I)$ from water.
\end{abstract}

Key words: Zeolite, Persimmon tannin, Impregnation, Radionuclide, Adsorption, Cs(I) removal

\section{Introduction}

The radioactive materials are extensively used in various industrial and research activities for medical, military, energy production and in various other areas. During the production and application of these materials, radioactive contamination could be brought about due to abundant un-reacted nuclides in the radioactive effluents ${ }^{1}$. The treatments of such radioactive effluents require concentration of the dissolved metal ions followed by recovery and secure disposal. The $\mathrm{Cs}(\mathrm{I})$ is the rarest of the alkali metals has little economic value and no essential biological role. However, nuclear technology has resulted in the release of large amount of radioactive isotopes $\left({ }^{137} \mathrm{Cs}\right.$ and $\left.{ }^{134} \mathrm{Cs}\right)$ of $\mathrm{Cs}(\mathrm{I})$ into the environment ${ }^{2}$. The ${ }^{137} \mathrm{Cs}$ is most important radionuclide present in large volumes in liquid radioactive wastes ${ }^{3} .{ }^{137} \mathrm{Cs}$ has been a matter of serious concern because of its relatively long radioactive half-life $\left(t_{1 / 2}=\sim 30\right.$ year), highly penetrating power and higher water solubility ${ }^{4,5}$. Thus, hazardous quantities of ${ }^{137} \mathrm{Cs}$ will remain in the environment for centuries. The living organisms easily absorb ${ }^{137} \mathrm{Cs}$ and replacing it for harmless $\mathrm{K}(\mathrm{I})$ or $\mathrm{Na}(\mathrm{I})$ ion. Thus, the nuclear industry is currently faced with increasing concern and anxiety over the radiological hazards to the human beings ${ }^{6}$. In this regard, an effective treatment system is required for the removal of $\mathrm{Cs}(\mathrm{I})$ from aqueous radiotoxic nuclides. This type of liquid wastes could be treated using solid adsorbents, like zeolites, clay minerals and synthetic inorganic ion exchangers, concentrating the radionuclides in small volumes of solid wastes ${ }^{5,7}$.

* Corresponding author

$-119-$ 


\section{J. Nepal Chem. Soc., Vol.37, 2017}

Chemical precipitation, evaporation and ion exchange are some of the processes used for the removal of $\mathrm{Cs}(\mathrm{I})$ from aqueous solutions of low and intermediate level before being discharged to the environment. Among these processes, ion exchange appears to be the most effective to control radioactive wastes $^{8}$. Ion exchange is a relatively simple technology used to remove hazardous ions from aqueous solutions which has high affinity for the ion to be removed ${ }^{9}$. This process has been widely studied for the removal of radioactive elements from alkaline wastes and sometimes from acid radioactive wastes. The nature of non radioactive isotopes of $\mathrm{Cs}(\mathrm{I})$ is similar to the radioactive isotopes. They exist as monovalent cesium in aqueous solution and possess similar chemical properties so that non radioactive isotope of Cs(I) was study in this case and expected to be employed for the treatment of water contaminated with radioactive cesium from water.

In the recent years, the use of natural zeolites for the treatment of radioactive waste has increased because they are considered as potential adsorbents due to their high cation exchange capacities and low cost. The commercial ion exchange resin containing phenolic moieties are popular for the removal of $\mathrm{Cs}(\mathrm{I})$ ion from aqueous solution ${ }^{10,11}$. The persimmon waste containing polyphenolic compounds like tannin is very effective for the removal of radioactive metals such as uranium and thorium ${ }^{12}$. From the literature, the polyphenol rich waste material such as persimmon waste, persimmon tannin, waste tea leaves were demonstrated to be effective for the removal of $\mathrm{Cs}(\mathrm{I})$ from aqueous solution ${ }^{13-15}$. Direct use of radioactive cesium is prohibited in our laboratory therefore the non radioactive form of $\mathrm{Cs}(\mathrm{I})$ was used and expected to be employed also in the treatment of effluent containing radioactive $\mathrm{Cs}(\mathrm{I})$. Therefore in the present study PTIZ was used as an adsorbent for the removal of Cs(I) from water. The adsorption behaviors of $\mathrm{Cs}(\mathrm{I})$ was investigated by means of $\mathrm{pH}$ effect, adsorption kinetics, adsorption isotherms and adsorbent dosage from modeled solution.

\section{Experimental Methods}

\section{Material and chemicals}

The sample of persimmon tannin impregnated zeolite abbreviated hereafter PTIZ was kindly received from HiFuMi Sangyo (Hifumi industry) Co. Ltd., Gunma Prefecture, Japan. The adsorbent particle size was made $<75 \mu \mathrm{m}$ by crushing with morter and pestle and was utilized for the experimental runs. The stock solution $1000 \mathrm{mg} / \mathrm{L}$ of $\mathrm{Cs}(\mathrm{I})$ an $\mathrm{Na}(\mathrm{I})$ were prepared in deionized water using $\mathrm{CsCl}$ and $\mathrm{NaCl}$ salts (Wako Pure Chemical Industries, Ltd), respectively. From this stock solution the required concentration of $\mathrm{Cs}(\mathrm{I})$ an $\mathrm{Na}(\mathrm{I})$ solution was prepared by diluting with deionized water for fresh use.

\section{Batch wise adsorption test}

The batch adsorption tests of $\mathrm{Cs}(\mathrm{I})$ was carried out in order to observe their adsorption behavior onto persimmon tannin impregnated zeolite powder. In a typical set, $15 \mathrm{ml}$ of test solution containing predetermined amount of $\mathrm{Cs}(\mathrm{I})$ was added to $15 \mathrm{mg}$ of the PTIZ and the resulting mixtures were shaken in a thermo-stated shaker at $150 \mathrm{rpm}$ for $24 \mathrm{~h}$ except kinetic study. For kinetic study, $250 \mathrm{mg}$ of the PTIZ and $250 \mathrm{~mL}$ of $0.5 \mathrm{mmol} / \mathrm{L}$ of $\mathrm{Cs}(\mathrm{I})$ solution were stirred at $303 \mathrm{~K}$ at $\mathrm{pH} 6.7$ and sampled were collected at different time interval between 5 minute to 4 hour. After shaking, the samples were filtered and the concentration of $\mathrm{Cs}(\mathrm{I})$ ion was determined by using atomic absorption spectrometer (AAS). The $\mathrm{pH}$ of the $\mathrm{Cs}(\mathrm{I})$ solution was adjusted by adding some drops of either $0.1 \mathrm{M} \mathrm{HCl}$ or $0.1 \mathrm{M} \mathrm{NaOH}$ solution. The percentage adsorption (\% A) and $\mathrm{Cs}(\mathrm{I})$ uptake capacity were determined by using equation 1 and 2 , respectively. 
$\% A=\frac{C_{i}-C_{e}}{C_{i}} \times 100$

$q=\frac{C_{i}-C_{e}}{W} \times V$

Where, $C_{i}$ and $C_{e}$ are initial and equilibrium concentration (mmol/l) of $\mathrm{Cs}(\mathrm{I})$ respectively. W is weight of the adsorbent $(\mathrm{g})$ and $\mathrm{V}$ is volume of solution $(\mathrm{L})$.

\section{Results and discussion}

\section{Influence of contact time}

Adsorption kinetic of $\mathrm{Cs}(\mathrm{I})$ during the adsorption process is very important for the evaluation of adsorption rate and equilibrium time. Fig. 1 shows the effect of contact time for the adsorption of Cs(I) onto PTIZ. As can be seen from the result of this figure that initially $\mathrm{Cs}(\mathrm{I})$ was rapidly adsorbed onto the adsorbent then the rate of adsorption was gradually slow down and finally approaching a constant value. It can be noticed that curve of cesium adsorption onto the present adsorbent is characterized by fast adsorption and the equilibrium was reached within $1 \mathrm{~h}$ of contact time. The fast adsorption rate of Cs(I) on PTIZ reflects its tremendous affinity towards $\operatorname{Cs}(\mathrm{I})$ and is attributable to the accessibility of monovalent cesium ion to the cation exchange site of PTIZ. Although equilibrium was observed to be reached within $1 \mathrm{~h}$ at $0.5 \mathrm{mmol} / \mathrm{L}$ concentration of $\mathrm{Cs}(\mathrm{I})$, subsequent adsorption experiment were carried out for about $24 \mathrm{~h}$ in order to ensure complete equilibrium.

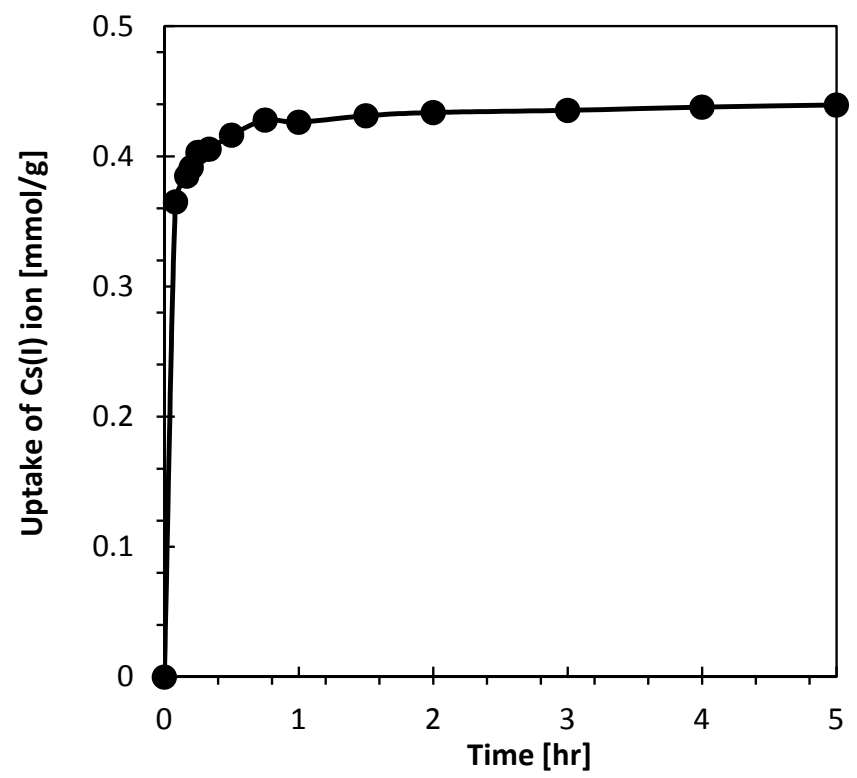

Figure 1: Adsorption kinetics of Cs(I) onto PTIZ (condition: Volume of solution $=250 \mathrm{ml}$, concentration of $C s=0.5 \mathrm{mM}$, wt of adsorbent $=250 \mathrm{mg}$, temp. $=303 \mathrm{~K}$ and shaking $=500 \mathrm{rpm}$ ). 


\section{J. Nepal Chem. Soc., Vol.37, 2017}

\section{Effect of pH and adsorption mechanism}

The $\mathrm{pH}$ is an important parameter to be considered in adsorption processes because it may affect both the properties of the adsorbent and the composition of the solution. As illustrated in Fig. 2, the percentage adsorption of $\mathrm{Cs}(\mathrm{I})$ increased with increasing the $\mathrm{pH}$. The result shows that the adsorption of $\mathrm{Cs}(\mathrm{I})$ was increase from $83 \%$ to $96 \%$ by increasing the $\mathrm{pH}$ from 2.8 to 4.6 whereas it was found to achieved nearly $100 \%$ at $\mathrm{pH}$ higher than 5.5. As we know that the structure of zeolite consists of three dimensional frameworks of Si-O and Al-O tetrahedral. The aluminium ion is small enough to occupy the position in the center of the tetrahedron of four oxygen atoms and the isomorphous replacement of $\mathrm{Si}^{4+}$ by $\mathrm{Al}^{3+}$ produces a negative charge in the lattice. The net negative charge is balanced by the exchangeable cation such as $\mathrm{Na}(\mathrm{I})$ or $\mathrm{K}(\mathrm{I})$ as shown in Scheme 1a.These positive ions are rather loosely held and can readily be exchanged with others in a contact solution during adsorption as shown in Scheme 2. Persimmon tannin contain polyphenol (for example Scheme 1b) where adsorption of Cs(I) occurs by chelation as demonstrated in Scheme 3. In the case of persimmon tannin impregnated zeolite (PTIZ ) powder due to the presence of both zeolite and polyphenol, the adsorption of $\mathrm{Cs}(\mathrm{I})$ occurs through both cation exchange as well as chelation mechanism therefore effective adsorption of $\mathrm{Cs}(\mathrm{I})$ onto PTIZ is possible.

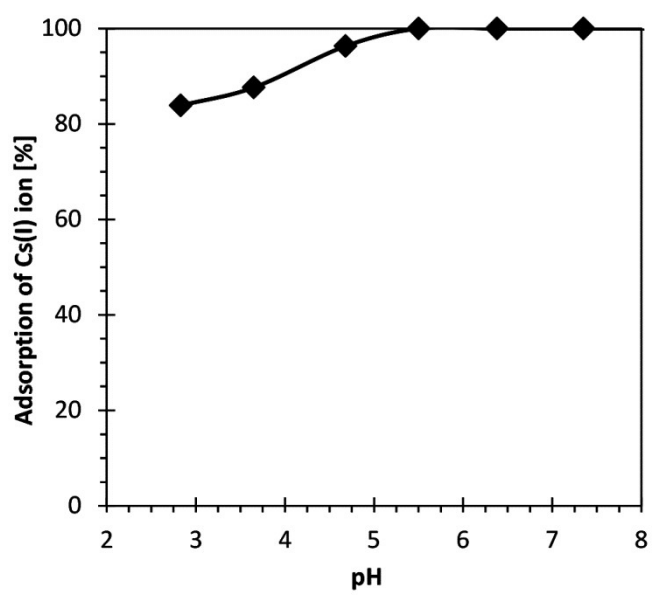

Figure 2: Effect of $\mathrm{pH}$ for the removal of cesium from aqueous solution onto PTIZ (condition: weight of dry $\mathrm{gel}=15 \mathrm{mg}$, volume of the solution $=10 \mathrm{~mL}$, concentration of $\mathrm{Cs}^{+}=60 \mathrm{mg} / \mathrm{L}$, temperature $=30^{\circ}$ Cand shaking ime<smiles>[Y][Al](O)(O[Si](O)(O)O[Al])O[Si](O)(O)O[Al+]</smiles>

$\mathrm{Si}$

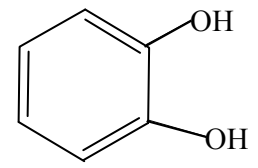

(b)

Scheme 1 (a) Structure of zeolite (b) structure of polyphenol (catecol). 
<smiles>[3H]O[Si](O)(O[Si])O[Si](O)(O[Si])O[Si](O)(O)O[Al]</smiles>

Zeolite<smiles>O[Si](O)(O[Al])O[Si](O)(O[Si])O[Si](O)(O)O[Si]</smiles>

Cs(I) adsorbed Zeolite

Scheme 2 Cs(I) adsorption mechanism by using zeolite via. cation exchange

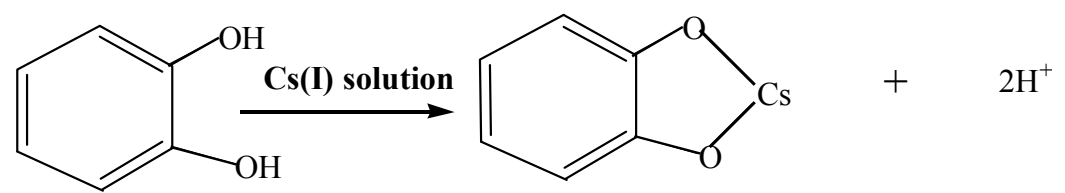

Scheme 3 Mechanism Cs(I) adsorption by chelation with polyphenolic group of persimmon tannin.

\section{Influence of $\mathrm{Cs}(\mathrm{I})$ concentration}

The influence of $\mathrm{Cs}(\mathrm{I})$ concentration during adsorption was tested in order to evaluate the maximum uptake capacity of persimmon tannin impregnated zeolite towards Cs(I). Fig. 3a shows the adsorption isotherm of persimmon tannin impregnated zeolite for $\mathrm{Cs}(\mathrm{I})$ at $\mathrm{pH}$ 6.7. As revealed by this figure, the amount of $\mathrm{Cs}(\mathrm{I})$ adsorbed on to the adsorbents increased with increasing $\mathrm{Cs}(\mathrm{I})$ concentration at lower concentration region where as it approached a constant values at higher concentration exhibiting typical Langmuir type monolayer adsortion. The experimental data was modeled by using well known Langmuir and Freundlich isotherm equations as depicted by equation 3 and 4 respectively. Langmuir isotherm can be expressed in the form of following equation (Eq. 3) as ${ }^{16}$

$$
\frac{C_{e}}{q_{e}}=\frac{1}{q_{\max } b}+\frac{C_{e}}{q_{\max }}
$$

where, $\mathrm{C}_{\mathrm{e}}(\mathrm{mmol} / \mathrm{L})$ and $\mathrm{q}_{\mathrm{e}}(\mathrm{mmol} / \mathrm{g})$ are equilibrium concentration and amount of adsorption, respectively, while $\mathrm{q}_{\max }$ is the maximum loading capacity and $\mathrm{b}$ is the ratio of adsorption/desorption rate related to energy of adsorption. The $\mathrm{q}_{\max }$ and $\mathrm{b}$ were calculated from the slope and intercept of the linear plot of $\mathrm{C}_{\mathrm{e}} / \mathrm{q}_{\mathrm{e}}$ versus $\mathrm{C}_{\mathrm{e}}$ (Fig. 3b) and presented in Table 1. Similarly, Freundlich isotherm can be expressed in its linear form as ${ }^{17}$

$\log \mathrm{q}_{\mathrm{e}}=\log \mathrm{K}_{\mathrm{F}}+(1 / \mathrm{n}) \log \mathrm{C}_{\mathrm{e}}$ (4)

where $\mathrm{K}_{\mathrm{F}}$ and $\mathrm{n}$ are Freundlich constants related to the adsorption capacity and adsorption intensity, which can be calculated from the intercept and slope of the linear Freundlich plot of $\log \mathrm{q}_{\mathrm{e}}$ versus $\log \mathrm{C}_{\mathrm{e}}$ (Fig. 3c). The evaluated values of $K_{F}$ and $n$ are also listed in Table 1. The value of correlation regression coefficient in case of Langmuir isotherm model $\left(\mathrm{R}^{2}\right.$ value higher than 0.99$)$ is comparatively higher than that obtained from Freunlich isotherm model (where $\mathrm{R}^{2}$ value less than 0.93 ) which strongly suggest that the experimental data is better fitted with the Langmuir isotherm, which strongly suggest the formation of monolayer $\mathrm{Cs}(\mathrm{I})$ on the surface of PTIZ. The maximum adsorption capacity and Langmuir equilibrium 


\section{J. Nepal Chem. Soc., Vol.37, 2017}

constant evaluated using Langmuir isotherm model was found to be $1.24 \mathrm{mmol} / \mathrm{g}$, and $3.34 \mathrm{~L} / \mathrm{mmol}$, respectively.

The Langmuir equilibrium constant $\mathrm{b}$ can be utilized to investigate the suitability of adsorption process by calculating a dimensionless separation factor $\left(\mathrm{R}_{\mathrm{L}}\right)$ according to the equation as ${ }^{18}$

$$
R_{L}=\frac{1}{1+b C_{i}}
$$

where $b$ and $\mathrm{C}_{\mathrm{i}}$ are Langmuir equilibrium constant, initial concentration of $\mathrm{Cs}(\mathrm{I})$ ion, respectively. The value of $R_{L}$ determines the nature of adsorption process. Zero value of $R_{L}$ indicates irreversible nature of adsorption whereas if it is equals to one then the adsorption process is linear. In the case if the value of $R_{L}$ is greater than one indicating unfavorable nature of adsorption and the value of $R_{L}$ in between 0 and 1 showing favorable nature of adsorption process ${ }^{16}$. It was found that the value of $R_{L}$ at different initial concentration tested in this study were in between 0 and 1 i.e. $0<\mathrm{R}_{\mathrm{L}}<1$, which strongly suggest that the adsorption of Cs(I) onto PTIZ is favorable

Table 1 Freundlich and Langmuir parameters for the adsorption of $\mathrm{Cs}(\mathrm{I})$ onto $\mathrm{PTIZ}$ at $=30^{\circ} \mathrm{C}$.

\begin{tabular}{|l|l|l|}
\hline \multirow{5}{*}{ Freundlich parameters } & Isotherms parameters & Calculated value \\
\cline { 2 - 3 } & $\mathrm{K}_{\mathrm{F}}(\mathrm{mmol} / \mathrm{g})$ & 0.97 \\
\cline { 2 - 3 } & $1 / \mathrm{n}$ & 0.23 \\
\cline { 2 - 3 } & $\mathrm{R}^{2}$ & 0.92 \\
\hline Langmuir parameters & $q_{\text {max.. }}(\mathrm{mmol} / \mathrm{g})$ & 1.24 \\
\hline & $\mathrm{b}(\mathrm{L} / \mathrm{mmoL})$ & 3.34 \\
\hline & $\mathrm{b}(\mathrm{L} / \mathrm{mmoL})$ & 3.34 \\
\hline & $\mathrm{R}^{2}$ & 0.99 \\
\hline
\end{tabular}

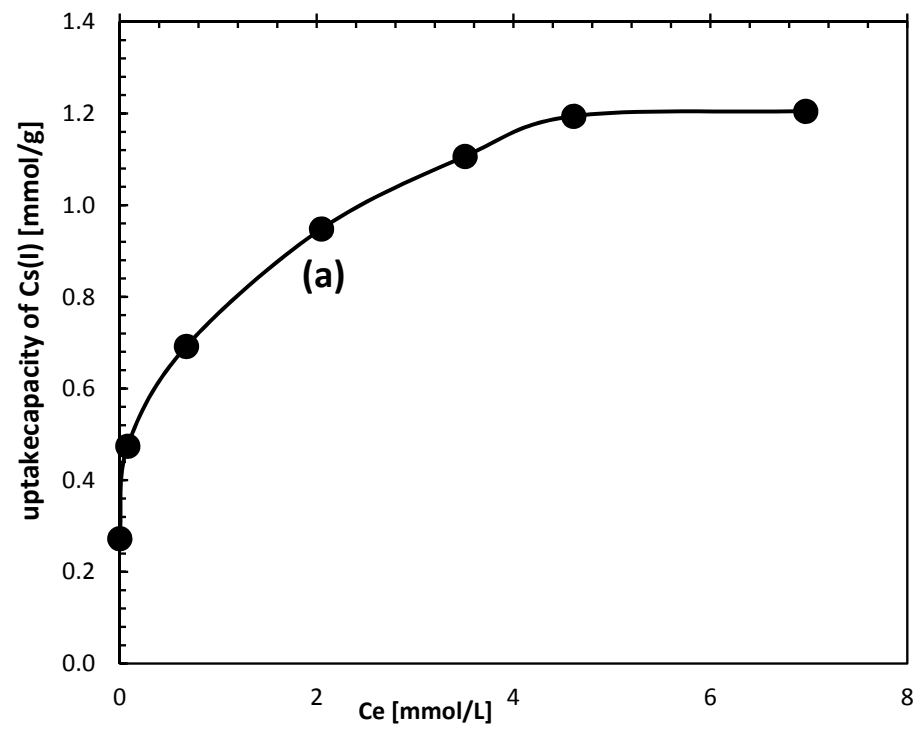

$-124-$ 

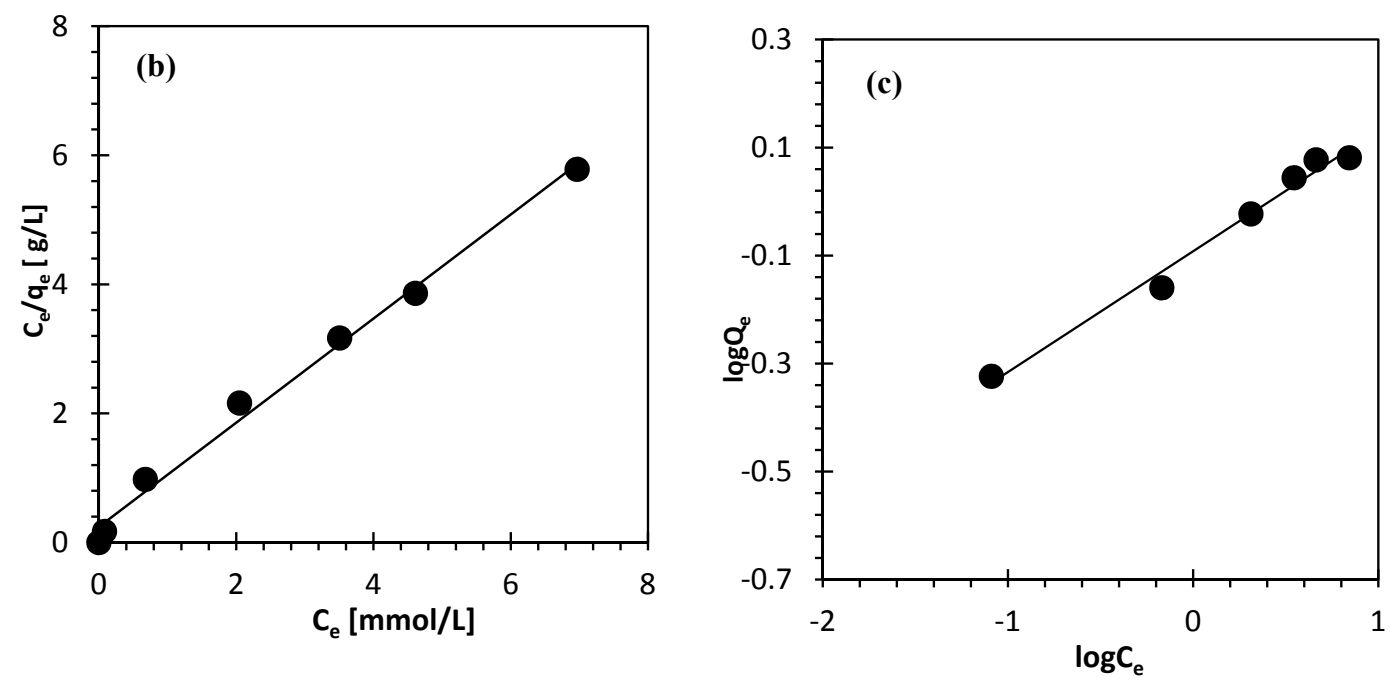

Figure 3: Adsorption isotherms of Cs(I) onto persimmon tannin impregnated zeolite from aqueous solution (a) experimental isotherm plot, (b) Langmuir plot, and (c) Freundlich plot (conditions: Volume of solution $=10$ $\mathrm{ml}$, wt of gel $=15 \mathrm{mg}$, temp $=30^{\circ} \mathrm{C}$, shaking time $=48 \mathrm{~h}$, and shaking speed $=150 \mathrm{rpm}$ ).

\section{Effect of adsorbent dose}

In order to optimize the dosage of the adsorbent to the $\mathrm{Cs}(\mathrm{I})$ adsorption, the experiment was conducted by using $8.7 \mathrm{mg} / \mathrm{L}$ of $\mathrm{Cs}(\mathrm{I})$ solution prepared at deionized water. The result is shown in Fig.4, which presents the plot of residual $\mathrm{Cs}(\mathrm{I})$ concentration as a function of solid-liquid ratio. The results clearly suggests that the concentration of $\mathrm{Cs}(\mathrm{I})$ was decreased from $8.7 \mathrm{mg} / \mathrm{L}$ to $0.53 \mathrm{mg} / \mathrm{L}$ by using $0.5 \mathrm{~g} / \mathrm{L}$ of PTIZ whereas it was found to achieved at zero or $100 \%$ removal by using $1 \mathrm{~g} / \mathrm{L}$ or higher dosage. From this result, the PTIZ is effective for the complete removal of trace concentration of Cs(I) polluted.

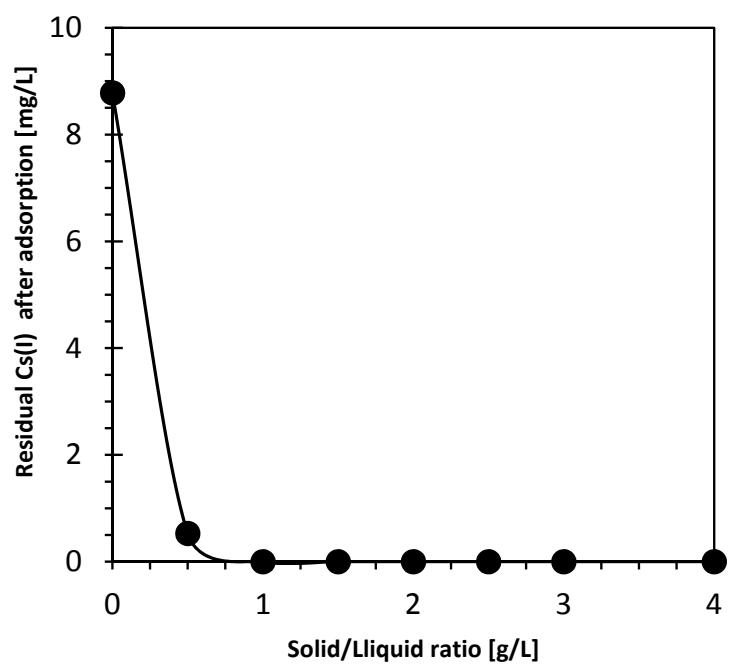

$-125-$ 


\section{J. Nepal Chem. Soc., Vol.37, 2017}

Figure 4: Effect of adsorbent dose for the removal of Cs(I) onto persimmon tannin impregnated zeolite (conditions: volume of the solution used $=10 \mathrm{ml}$, Cs(I) concentration $=8.72 \mathrm{mg} / \mathrm{L}$, solution $\mathrm{pH}=5.76$, shaking time $=24 \mathrm{~h}$, shaking speed $=150 \mathrm{rpm}$ and temperature $=30^{\circ} \mathrm{C}$ ).

\section{Conclusions}

The feasibility of using PTIZ for the rapid removal of $\mathrm{Cs}(\mathrm{I})$ from water was studied in the present work and following conclusions could be drawn from this study:

- Efficient and rapid adsorption of $\mathrm{Cs}(\mathrm{I})$ took place within only $1 \mathrm{~h}$ contact time.

- Batch adsorption studies showed approximately $100 \%$ removal of $\mathrm{Cs}(\mathrm{I})$ at $30^{\circ} \mathrm{C}$ from mixed solution containing trace concentration of $\mathrm{Cs}(\mathrm{I})$ ion which suggest high selectivity of PTIZ for Cs(I) ion.

- Isotherm study proved Langmuir type monolayer adsorption of Cs(I) on the surface of PTIZ.

- Therefore, the PTIZ investigated in this study can be offer to be a promising candidate for the treatment of water or waste water contaminated with $\mathrm{Cs}(\mathrm{I})$ ion.

\section{References}

1. H. Paudyal, B. Pangeni, K. Inoue, K. Ohto, H. Kawakita, K.N. Ghimire, H. Harada and S. Alam, Sep. Sci. Technol (2014), 49, 1244-1250.

2. A.E. Osmanliouglu, J. Hazard. Mater. 2006, 137, 332-335.

3. D. Ding, Y. Zhao, S. Yang, W. Shi, Z. Zhang, Z. Lei, Y. Yang, Water Res. 2013, 47, 2563-2571.

4. R.J. Rad, H. Ghafourian, Y. Asef, S.T.Dalir, M.H. Sahafipour and B.M. Gharanjik, J. Hazard. Mater. 2004, B116, 125-134.

5. T. Sangvanich, V. Sukwarotwat, R.J. Wiacek, R.M. Grudzien, G.E. Fryxell, R.S. Addleman, C. Timchalk, W. Yantasee, J. Hazard. Mater. 2010, 182, 225-231.

6. K.C. Song, H.K. Lee, H. Moon, K.J. Lee, Sep. Purif. Technol. 1997, 12, 215-217.

7. A.M. EI-Kamash, J. Hazard. Mater. 2008, 151,432-445.

8. S. Hasan, T.K.Ghos, D.S. Viswanath, S.K. Loyalka, B. Sengupta, Sep. Sci. Technol. 2007, 42, 717-738.

9. H. Paudyal, B.a Pangeni, K. Inoue, H. Kawakita, K. Ohto, K.N. Ghimire and S. Alam, Biores. Technol. 148, 221-227.

10. S.K. Samanta and M. Ramaswamy, Sep. Sci. Technol. 1992, 27, 255 -267.

11. T. Sakaguchi, A. Nakajima, Recovery, Sep. Sci. Technol. 1987, 22, 1609-1623.

12. K. Inoue, H. Kawakita, K. Ohto, T. Oshima, H. Murakami, J. Radioanal. Nucl. Chem. 2006, 267, 435-442.

13. B. Pangeni, H. Paudyal, K. Inoue, H. Kawakita, K. Ohto, S. Alam, Chem. Eng. J. 2014, 242, 109-116.

14. B. Pangeni, H. Paudyal, K. Inoue, K. Ohto, M. Gurung, H. Kawakita, S. Alam, Waste and Biomass Valorization 2014, 5(6), 1019-1028.

15. M. Gurung, B.B. Adhikari, S. Alam, H. Kawakita, K. Ohto, K. Inoue, H. Harada, Chem. Eng. J. 2013, 231, 113-120.

16. I. Langmuir, J. Am. Chem. Soc. 1916, 38, 2221- 2295.

17. H. Freundlich, J. Phys. Chem. 1906, 57, $385-470$.

18. C.L. Xia, Y. Jing, Y.Z. Jia, D.Y. Yue, J. Ma and X.J.Yin, Desalination 2011, 265, 81- 87. 